\title{
Turismo de base comunitária em territórios rurais: caso da Associação de Agroturismo Acolhida na Colônia (SC)
}

\section{Community-based tourism in rural areas: the case of the Associação de Agroturismo Acolhida in Colônia (SC, Brazil)}

\section{Thaise Costa Guzzatti, Carlos Alberto Cioce Sampaio, Luzia Neide Menezes Teixeira Coriolano}

\begin{abstract}
RESUMO
Discussões sobre temáticas do turismo e agricultura são bastante amplas e abrangem considerável conjunto de perspectivas teóricas. Aborda-se alguns elementos destas temáticas, especialmente aqueles que no seu conjunto contestam a tipologia predominante de turismo, o de massa, e discute a emergência de alternativas, tal como turismo de base comunitária. Frente à urgência de fomento de iniciativas que possibilitem diversificação das atividades nas propriedades familiares de produção, o agroturismo desponta como estratégia de geração de trabalho e renda. A atividade potencializa ainda ganhos sociais e ambientais, permitindo o enfrentamento do avanço da produção industrial (ou agricultura patronal, como mais frequentemente é conhecida) no campo e dizimação do modo de vida, produção e conhecimento tradicional dos agricultores familiares. Toma-se como referencia o caso da Associação de Agroturismo Acolhida na Colônia, com sede em Santa Rosa de Lima (SC). Objetivo do trabalho é discutir benefícios gerados pelo agroturismo para fortalecimento da agricultura familiar, além de identificar fatores limitantes para seu desenvolvimento. Pode-se observar, após análise do caso da Acolhida na Colônia, que agroturismo gera oportunidades aos agricultores e municípios onde a atividade é desenvolvida, encontrando, no entanto, fatores limitantes para seu desenvolvimento.
\end{abstract}

PALAVRAS-CHAVE: Turismo de Base Comunitária; Agricultura Familiar; Agroturismo. 
Turismo de base comunitária em territórios rurais: caso da Associação de Agroturismo Acolhida na Colônia (SC)

\begin{abstract}
Discussions with tourism and agricultural themes are very wide and comprehend a considerable group of theoretical perspectives. Some elements of these themes are approached here, especially those that, in their group, question the predominant typology of tourism, the one of the masses, and discusses the emergence of alternatives such as the community-based tourism. With the urgency to have fomentation for the initiatives that make the diversification of activities in family producing properties possible, the agrotourism rises as a strategy for generating employment and income as well as potentializing social and environmental gain to the agriculturists and their families, enabling the confrontation to the stride of the industrial production (more commonly known as patronal agriculture) in the fields and decimation of their lifestyle, production and traditional knowledge of the family-based agriculturists. The Agrotourism Association Acolhida da Colônia with its headquarters in Santa Rosa de Lima (SC) is taken as a reference case. The objective of this study is to discuss the benefits generated by the agrotourism for the strengthening of the family-based agriculture and also identify limiting factors for its development. It is possible to observe, after the analysis of the Acolhida da Colonia case that the agrotourism generates opportunities for the agriculturists and the towns where the activities take place, nonetheless existing limiting factors for its development have been observed.
\end{abstract}

KEYWORDS: Community-Based Tourism; Family-Agriculture; Agrotourism.

\title{
Introdução
}

Existem fortes indicativos de que modelos predominantes de agricultura e turismo, tais como agricultura patronal e turismo de massa, tem sido incapazes de responder à problemas brasileiros contemporâneos, sejam eles fome e pobreza, vulnerabilidade social, insustentabilidade ambiental, direito a terra, direito das mulheres, dentre tantos outros desafios ecosocioeconômicos.

No que tange à agricultura, estudo realizado pela FAO/INCRA em 1994 aponta para a existência, no Brasil, de dois modelos: patronal e familiar. Na agricultura familiar, segundo referido estudo, existe íntimo relacionamento entre gestão e trabalho, sendo o processo produtivo dirigido pelo agricultor e havendo ênfase na diversificação da produção. Trabalho assalariado é apenas complementar. Decisões são imediatas, adequadas ao alto grau de imprevisibilidade e especificidades do processo produtivo e tomadas in loco, priorizando-se o uso de insumos internos. Outra característica do modelo familiar é aliar qualidade de vida e conservação dos recursos naturais.

No caso da agricultura patronal, acontece total separação dos fatores gestão e trabalho, sendo a organização do processo produtivo centralizada; produção baseada na especialização e em práticas agrícolas padronizáveis, havendo predomínio do trabalho assalariado; saberes são desvalorizados frente as tecnificações; práticas em- 
pregadas buscam principalmente reduzir mão de obra e ao mesmo tempo criam dependência no uso de insumos mercantilizados (FAO/INCRA, 1994).

Segundo análises feitas pela FAO/INCRA (1994 e 1996), a agricultura patronal contrata número limitado de trabalhadores residentes e fomenta forte concentração de renda e exclusão social. Em contrapartida, agricultura familiar apresenta perfil essencialmente distributivo e possibilita maior equidade sociocultural. Este modelo apresenta vantagens com relação à estabilidade e à capacidade de adaptação, devido à ênfase na diversificação e maior maleabilidade do seu processo decisório.

No entanto, apesar dos argumentos favoráveis ao fomento da agricultura familiar e sua representatividade em número de propriedades rurais no Brasil ${ }^{1}$,na maioria da vezes as políticas públicas do país privilegiam a agricultura patronal, sob o pretexto do crescimento econômico, se contrapondo aos impactos sociais e ambientais da atividade.

Veiga (2002), baseando-se na análise dos impactos da estratégia de desenvolvimento agrícola adotada pelos Estados Unidos, afirma que espaços que foram dominados pela agricultura mais tecnificada são os que menos favorecem ao dinamismo regional, mesmo exibindo altos níveis de eficiência. Para ele,

(...) são paisagens tão monótonas, com águas e solos tão contaminados por agroquímicos que não podem aproveitar uma das principais vantagens comparativas das zonas rurais do século 21: a atração de residentes temporários, aposentados, famílias em férias, turistas, esportistas, congressistas, sem falar nas empresas que a revolução telemática está libertando dos grilhões urbanos. No limite, deve-se até admitir o inverso do senso comum, pois a agricultura de ponta pode se transformar no maior vilão do desenvolvimento rural (VEIGA, 2002, p.72).

Pode-se recordar o alerta de Brose (1999), na ocasião que comenta sobre consequências do abandono do campo pelos agricultores familiares devido às condições de vida cada vez mais precárias nas zonas rurais. Afirma o autor que

o fechamento e o abandono de uma unidade familiar de produção constitui uma catástrofe cultural, social e econômica para a referida família. Ele acarreta a perda (muitas vezes de forma irreversível) da autonomia, do modo de vida, da autoestima da família, para o subemprego e a insegurança alimentar. Constitui na verdade uma perda para toda a sociedade, e muitas vezes é o caminho certo para a cesta básica e para chagas sociais como a prostituição infantil (BROSE, 1999, p. 14-15).

Dentro das estratégias traçadas pela agricultura familiar para garantir sua manutenção e reprodução surge discussão sobre novos papéis do meio rural e, consequentemente, dos agricultores, no qual o turismo encontra espaço para se desenvol- 
Turismo de base comunitária em territórios rurais: caso da Associação de Agroturismo Acolhida na Colônia (SC)

ver. Neste contexto, o objetivo do trabalho é discutir benefícios gerados pelo agroturismo para fortalecimento da agricultura familiar, além de identificar fatores limitantes para o desenvolvimento.

\section{Turismo comunitário e superação do turismo de massa}

Turismo conhecido é o de turismo de massa, com deslocamento de grande número de pessoas, em mesmo período do ano, para destinos consagrados. Turismo de massa é criticado no que se refere às consequências da dinâmica socioecológica (TRIGO, 1993; URRY, 1996; SAMPAIO, 2004; CORIOLANO; SILVA, 2005; CORIOLANO, 2006; BURSZTYN et al., 2009; ZAQUAL, 2009). Para Bursztyn et al. (2009, p.77), turismo de massa "compromete as condições sociais, prejudica as condições ambientais e descaracteriza as heranças culturais de comunidades tradicionais".

Em contraposição ao turismo de massa, emerge a prática de turismo sustentável, fruto da mobilização de comunidades rurais, pesqueiras, indígenas, quilombolas, conhecido como turismo solidário, turismo comunitário e ainda turismo responsável.

Para Silveira (2001), o turismo sustentável é aquele que atende as necessidades dos turistas e das populações locais no presente, sem por em risco a capacidade das gerações futuras de atender as suas necessidades. Ele deve ter como principais objetivos a sustentabilidade ecológica, a equidade social e a eficácia econômica.

Experiências de turismo comunitário no Nordeste e Norte do país são realizadas de forma integrada às demais atividades econômicas, com iniciativas que fortalecem a agricultura, a pesca, o artesanato, dentre outras atividades, prioriza geração de trabalho para dinamização do capital local, garantindo oportunidade de participação comunitária nas decisões sobre políticas públicas (CORIOLANO, 2006). Mais do que planejamento descentralizado e associativo, busca contribuir para que reivindicações sociais das comunidades ganhem pauta e visibilidade como temas de interesse, tais como luta pela regulamentação fundiária e posse da terra.

Se por um lado, o turismo comunitário surge como reivindicação das comunidades para que estejam inseridas na cadeia produtiva do turismo, podendo participar e se beneficiar da atividade, por outro lado, turismo comunitário encontra espaço de expansão pela tomada de consciência de que lazer e turismo podem ser associados a prática de responsabilidade social.

Brandão (2011), analisando esse turismo, admite que é o interesse pelo outro, sem o fetiche da mercantilização que é essencial. O autor diz que

(...) a ideia de que viajamos não apenas para ver (fotografar), mas para perceber e vivenciar. E não apenas para perceber, mas para compreender. Compreender o outro através de mim mesmo; compreender a si mesmo através do outro. Compreender a vida e os mistérios no essencial encontro humano: o entre nós (p. 32). 

de iniciativa

Sampaio (2010), ao escrever sobre turismo comunitário, conclui que neste tipo

(...) não se busca somente equidade na distribuição dos ingressos econômicos. Tudo está condicionado ao desejo e à capacidade de acoIher visitantes (turistas) - e não o inverso - com resguardo cultural, possibilitando conhecer um outro modo de vida, com os conhecimentos tradicionais que lhe são inerentes, distanciando do padrão urbanoconsumista. De qualquer maneira, não existe o aprimoramento econômico tantas outras vezes apresentado pelo princípio - a satisfação do clientes é nosso maior desejo -, e sim a busca da convivialidade, a primazia da troca solidária distanciada do interesse calculado (p. 109).

Alemberg Quindins, criador da Fundação Casa Grande Memorial do Homem Kariri (CE) considera que este aspecto essencial do turismo de base comunitária, trocas entre visitantes e visitados, promove um turismo de conteúdo, pelo crescimento humano que a atividade proporciona. Seria, segundo ele, uma contraposição ao turismo de puro consumo, chamado de turismo vazio, por pouco contribuir para o crescimento pessoal e para o desenvolvimento local. Neste sentido, Guzzatti (2010) relata o surgimento do movimento slow travel, o qual critica os pacotes turísticos tradicionais que oferecem roteiros com muitos destinos num período curto de tempo. Geralmente, nestes casos, os turistas voltam para casa com muitas fotos e poucas informações dos lugares visitados. Na concepção do slow travel, um dos elementos definidores da viagem é a oportunidade de tornar-se parte da vida local e se conectar ao lugar e ao povo.

Para melhor compreensão deste tipo de turismo classificado como comunitário, a próxima secção apresenta a experiência da Associação Acolhida na Colônia.

\section{Associação de Agroturismo Acolhida na Colônia}

Associação de Agroturismo Acolhida na Colônia foi fundada, no Brasil, em 1999, no território das Encostas da Serra Geral, no Estado de Santa Catarina (Figura 1).

A Acolhida na Colônia é ligada a associação Accueil Paysan, criada na França em 1987 e atualmente presente em 33 países de 4 continentes.

Na França, a entidade surge como fruto da reflexão de um grupo de agricultores, apoiados por pesquisadores ligados a questão da educação popular e sociólogos, sobre rumos da agricultura e possibilidades de desenvolvimento do agroturismo naquele país. A agricultura francesa, naquele período, atravessava momento de forte adaptação. Ganhos de produtividade e a eficácia de técnicas modernas conduziram a uma superprodução dentro da maioria das atividades classificadas como pilares da agricultura, gerando excedentes agrícolas. O preço mundial destes produtos estava frágil e a Comunidade Econômica Europeia possuía programas para sustentá-los. Es- 
Turismo de base comunitária em territórios rurais: caso da Associação de Agroturismo Acolhida na Colônia (SC)

ta prática garantia renda aos agricultores e os induzia a produzir sempre mais. Isso gerou um déficit de muitos milhões de dólares. Apesar das soluções traçadas para tentar limitar a produção (cotas, pousio de terras, etc.), os preços continuaram baixos, ocasionando a eliminação dos agricultores mais fracos ou moradores de zonas rurais difíceis. Muitos dos que permaneceram tiveram que buscar atividades alternativas.

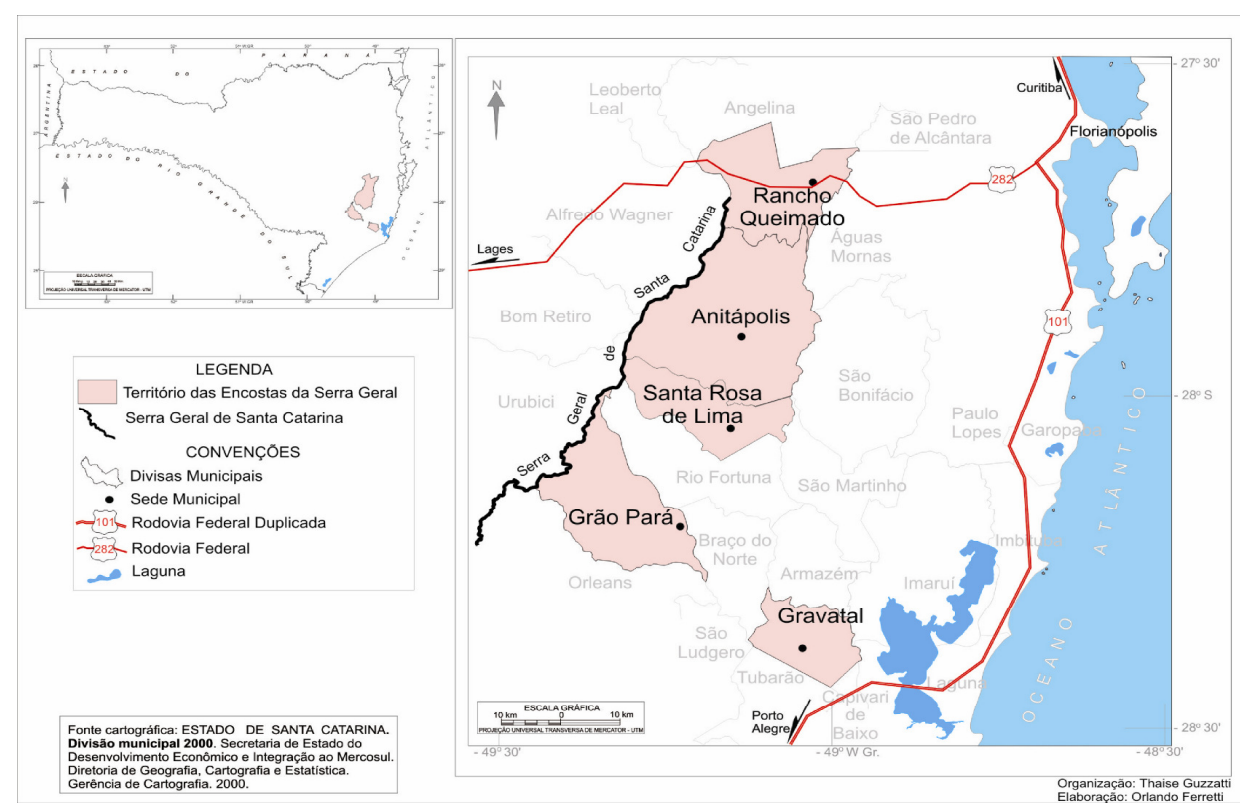

Figura 1: Território das encostas da Serra Geral, segundo a Associação Acolhida na Colônia. Fonte: Guzzatti (2010).

Figure 1: Territory from the slopes of the Serra Geral, according to the Associação Acolhida na Colônia.

Source: Guzzatti (2010).

É neste contexto que os fundadores da Accueil Paysan, originários dos Alpes Franceses (topografia e clima que limitam a expansão agrícola), colocam a questão da (re)apropriação de seu futuro por meio do controle da produção, no ganho nos circuitos curtos de distribuição e por uma autonomia mais completa do trabalho pelos serviços, especialmente o agroturismo. Esta atividade permitia combinar o trabalho da terra, a utilização do espaço e do ambiente natural e proporcionava a recuperação da autoestima; a geração de trabalho e renda; a dinamização das comunidades rurais, levando ao estabelecimento de novo laços sociais, especialmente entre campo e cidade.

No Brasil, os municípios que compõem o território das Encostas da Serra Geral, berço da Acolhida na Colônia - extensão brasileira da Accueil Paysan, são marcados pela presença da agricultura familiar como base de sua vida econômica e social. Deve-se destacar que, embora com menos intensidade devido às limitações físicas impostas pela declividade do solo, também neste território percebe-se os impactos ocasionados pela modernização da agricultura (GUZZATTI, 2003; 2010). Com relação a estes impactos, Guzzatti destaca que 
(...) a modernização a que foi submetida a agricultura brasileira resultou (e ainda resulta) no acúmulo de capital por parte das grandes empresas integradoras e dos grandes proprietários rurais; ocasionou (e ocasiona) prejuízos ambientais; provocou (e provoca) a contaminação dos alimentos (com prejuízos para a saúde de quem produz e de quem consome) e, principalmente, levou (e leva) ao empobrecimento e à exclusão social pessoas que historicamente foram responsáveis pela alimentação da população brasileira (GUZZATTI, 2010, p. 55)

Neste contexto, os municípios das Encostas da Serra Geral enfrentam uma série de dificuldades relacionadas ao desenvolvimento da agricultura familiar. Não raro, nestes municípios, a venda de terras para sitiantes, a exploração da mata nativa para a fabricação de carvão vegetal ou o reflorestamento tem sido a alternativa encontrada por muitos de seus agricultores para suprirem suas necessidades básicas (mesmo que na maioria das vezes essa escolha acabe piorando suas condições de vida e saúde). As dificuldades encontradas pelos agricultores têm provocado um forte processo de esvaziamento populacional e de empobrecimento no meio rural, com claros reflexos negativos sobre o seu patrimônio cultural e ambiental (GUZZATTI, 2003).

Diante da degradação econômico e social vivida pelo território das Encostas da Serra Geral, em 1996, um grupo de pessoas, na maioria filhos da terra que haviam migrado para núcleos urbanos maiores e seguido profissões não relacionadas a agricultura, iniciam reflexão sobre alternativas viáveis para a melhoria da qualidade de vida das famílias que permanecem nas Encostas da Serra Geral.

A primeira proposta foi a da implantação da produção de alimentos orgânicos, com venda garantida em rede de supermercados de proprietários oriundos de Santa Rosa de Lima, município da Encostas da Serra Geral. Assim, em 1996, doze famílias começaram o cultivo de alimentos sem uso de agrotóxico e outros insumos químicos, fundando a Associação dos Agricultores Ecológicos das Encostas da Serra Geral (Agreco).

Este foi o deslanchar de um processo de desenvolvimento territorial, com papel central desempenhado pela Agreco. Como decorrência do processo, inicia-se a expansão do número de produtores orgânicos; a implantação de pequenas agroindústrias rurais para o beneficiamento da produção; a implantação da cooperativa de crédito rural; a criação do centro de formação para jovens, dentre outras iniciativas.

Uma das consequências foi o interesse de agricultores, técnicos e consumidores de outras localidades para conhecer as atividades produtivas e as ações implementadas nas Encostas da Serra Geral. Desta forma, vislumbrou-se nova oportunidade para agricultores da região com oferta de serviços turísticos nas propriedades.

Neste caso, a atividade proposta foi o agroturismo. Desde o início a opção foi de utilizar um conceito que demarcasse de forma clara o segmento turístico trabalhado, evitando confusões entre agricultores e/ou turistas que poderiam achar que se tratava da proposição de atividades de turismo rural, este segmento relacionado com ho- 
Turismo de base comunitária em territórios rurais: caso da Associação de Agroturismo Acolhida na Colônia (SC)

téis fazenda, principalmente em Santa Catarina. Assim, o agroturismo defendido pela Acolhida na Colônia é definido como:

Um segmento do turismo desenvolvido no espaço rural por agricultores familiares organizados, dispostos a compartilhar seu modo de vida, patrimônio cultural e natural, mantendo suas atividades econômicas, oferecendo produtos e serviços de qualidade, valorizando e respeitando o ambiente e a cultura local e proporcionando bem-estar aos envolvidos (GUZZATTI, 2003, p. 53).

As constatações iniciais do processo de implantação da atividade nas Encostas da Serra Geral, são:

a baixa autoestima dos agricultores com relação a sua profissão e ao seu território. Muitos diziam: "o que os turistas viriam fazer aqui neste meio do mato"? Ou então: "aqui ninguém vem, só vai", numa referência ao processo do êxodo rural vivenciado na região;

problemas de infraestrutura, especialmente no que diz respeito à péssima condição das estradas; à falta de sinalização e problemas relacionados à qualidade da energia elétrica e graves problemas ambientais, sobretudo com relação à derrubada da mata nativa para a fabricação do carvão vegetal ou implantação de reflorestamento; à utilização excessiva de agrotóxicos e à falta de saneamento básico das propriedades rurais (GUZZATTI, 2010, p. 123).

A opção em integrar a rede francesa Accueil Paysan ocorre em função de que os objetivo propostos no Estatuto da Acolhida na Colônia estarem próximos daqueles defendidos pela organização francesa. Além disso, a Accueil Paysan possuía grande experiência na atividade, possibilitando à Acolhida na Colônia uma forma de adaptação da metodologia e das estratégias de ações.

Dentre os principais objetivos estabelecidos no Estatuto da Acolhida na Colônia, destaca-se:

contribuir para a melhoria da qualidade de vida dos agricultores familiares a ela associados, pela organização de atividades de agroturismo enquanto fonte complementar de renda;

valorizar as atividades dos agricultores familiares associados, oferecendo alternativas para que permaneçam no meio rural, resgatando sua história e sua cultura e fortalecendo uma prática produtiva dentro dos princípios da agroecologia, de proteção e de recuperação do ambiente natural;

promover a integração entre campo e cidade através da troca de experiências, ao possibilitar o convívio dos agricultores familiares com os habitantes de centros urbanos;

organizar, em parcerias, no âmbito desta Associação, o desenvolvi- 
mento de produtos agroturísticos baseados em circuitos locais e regionais;

resgatar a identidade cultural dos agricultores familiares, enquanto forte ingrediente de cidadania, propiciando-Ihes um clima favorável para exposição de seus valores de cultura para a sociedade em geral;

possibilitar aos agricultores familiares associados a sua capacitação, formação e profissionalização nas atividades de agroturismo, ecologia e outros campos de conhecimentos relacionados ao desenvolvimento rural sustentável (ACOLHIDA NA COLÔNIA, 1999. p. 01-02).

Para o desenvolvimento do agroturismo nos municípios das Encostas da Serra Geral, a Acolhida na Colônia desenvolveu uma metodologia própria, composta por sete etapas principais. São elas: a) diagnóstico das características territoriais e estabelecimento de compromisso com o projeto; b) sensibilização dos agricultores do território sobre o agroturismo; c) diagnóstico participativo das propriedades rurais; d) fortalecimento do associativismo; e) implantação dos negócios (elaboração de projetos individuais e coletivos; realização de investimentos); f) capacitação e assistência técnica e g) promoção.

Cabe destacar que, antes da propriedade fazer a promoção usando a logomarca da Acolhida na Colônia, ela passa por uma certificação a partir da avaliação do cumprimento das regras previstas no Caderno de Normas da entidade (documento elaborado pela Acolhida na Colônia que define as regras mínimas para serviços de hospedagem; de alimentação; atividades de lazer; venda de produtos, dentre outros). Algumas regras são obrigatórias, não havendo tempo de adaptação a partir da adesão e em outros casos o agricultor tem um tempo para realizar as adaptações necessárias. A certificação é participativa, sendo que uma comissão de três pessoas (um técnico e dois agricultores) é organizada em cada região, formando o comitê de verificação. No período de certificação, o comitê de uma região vistoria a região vizinha e assim sucessivamente, sendo o processo repetido a cada dois anos. Somente depois de certificados os agricultores podem entrar no site e participar das ações promocionais.

Um dos principais pontos defendidos pela Acolhida na Colônia é a preservação do meio ambiente e da cultura local. Por conta disso, os agricultores que fazem parte da entidade optam pela produção orgânica dos alimentos.

Além disso, a entidade possui um projeto apoiado pela Bovespa Social \& Ambiental para implantação de tecnologias de energia renovável nas propriedades rurais (Projeto Roda d'água). A proposta é que as propriedades possam ser mais autônomas no que concerne a energia.

A entidade agrega vinte e quatro municípios, incluindo a iniciativa de expansão no município de Imbituba, junto a pescadores artesanais (Figura 2). Fazem parte da Acolhida na Colônia cento e setenta famílias associadas no conjunto dos municípios, 
Turismo de base comunitária em territórios rurais: caso da Associação de Agroturismo Acolhida na Colônia (SC)

os quais se encontram em momentos diferentes em termos de desenvolvimento turístico nas propriedades.

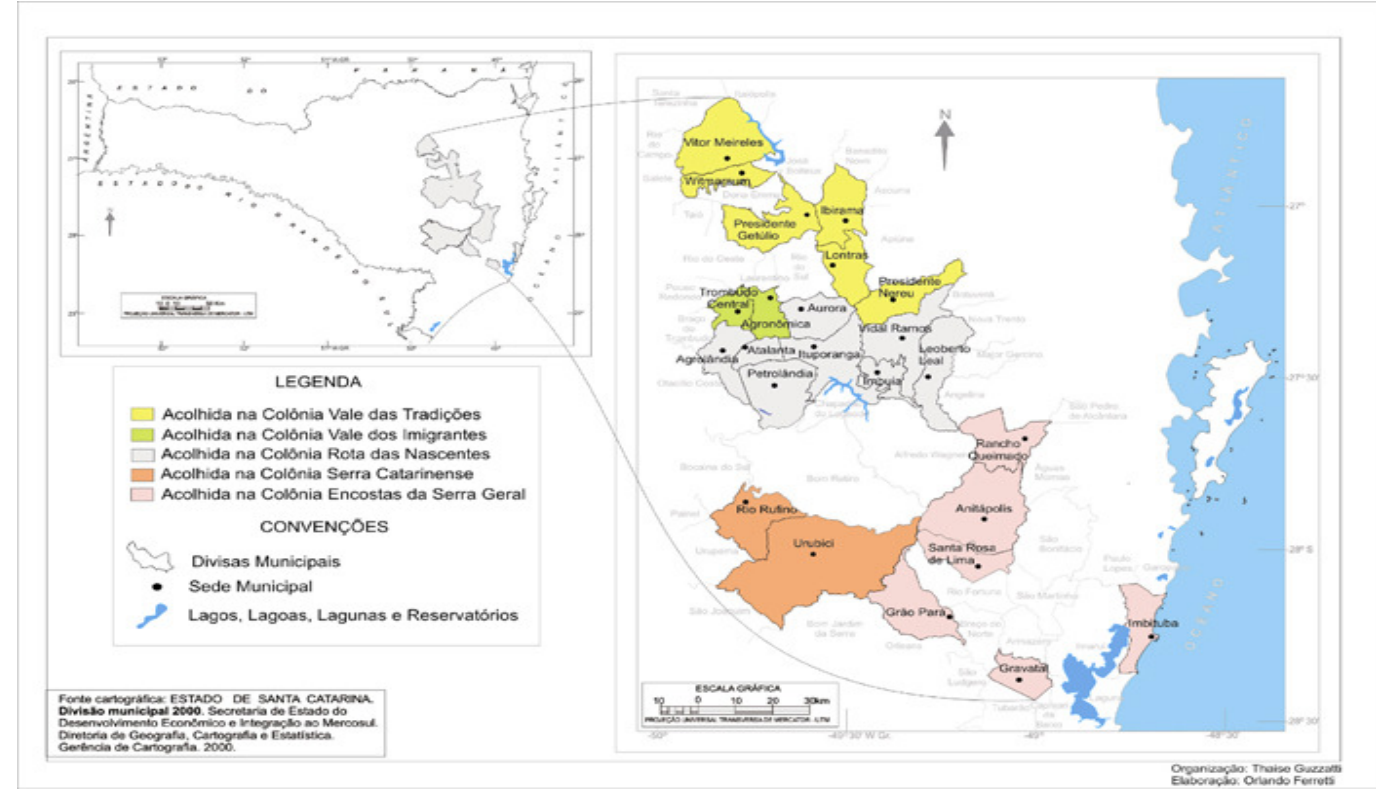

Figura 2: Área de abrangência da Associação Acolhida na Colônia. Fonte: Guzzatti (2010).

Figure 2: Area covered by the Associação Acolhida na Colônia. Source: Guzzatti (2010).

Como principais resultados do trabalho desenvolvido pela entidade, Guzzatti (2010) destaca os benefícios do agroturismo:

- mostra-se como uma importante opção de geração de trabalho e renda dentro das propriedades rurais;

- tem impacto na autoestima dos agricultores familiares;

- proporciona uma valorização das atividades rurais cotidianas;

- enaltece o lugar e o modo de vida dos agricultores;

- cria novas utilidades para instalações ociosas nas propriedades rurais, viabilizando a diversificação das atividades rurais;

- possibilita a troca de conhecimentos (viajar sem sair do lugar) para os agricultores;

- estimula o conhecimento de outras regiões do mundo, através de viagens de intercâmbio;

- atrai de forma expressiva o interesse de pessoas mais jovens;

- tem proporcionado o aumento da divulgação do território no estado e no país;

- facilita a captação de recursos públicos e privados por parte do Poder Público e da própria Acolhida; 
- valoriza as atividades ligadas à agricultura e à cultura local;

- contribui para o aumento da arrecadação de impostos municipais, graças ao melhor desempenho do comércio local.

Uma forma de reconhecimento da contribuição da iniciativa para a dinamização da agricultura familiar é demonstrada por meio dos prêmios recebidos pela Acolhida na Colônia durante sua existência. Destacam-se, neste contexto o Prêmio Destaque do Ministério do Desenvolvimento Agrário em 2002, promovido pelo Ministério do Desenvolvimento Agrário; Prêmio ODM (Objetivos de Desenvolvimento do Milênio) em 2005, promovido pela Organização das Nações Unidas - ONU; Prêmio Top de Agronegócios 2006, promovido pelo IPEQ - Instituto de Pesquisas da Qualidade e Ministério do Turismo; Destino Referência Nacional em turismo rural, Ministério do Turismo em 2007; Prêmio Generosidade da Editora Globo, em 2008.

No entanto, apesar dos resultados positivos identificados, o desenvolvimento do agroturismo acarretar problemas nos municípios e território em que é desenvolvido. Alguns destes problemas são identificados por Guzzatti (2010), sendo:

- a renda gerada na atividade agroturística provoca a redução da importância das atividades agropecuárias;

- a incompatibilidade entre o agroturismo e outras atividades da região vem acarretando conflitos de interesse. Em vários casos, os próprios visitantes denunciam habitantes locais que realizam atividades consideradas ilegais;

- a presença de pessoas mal intencionadas pode provocar transtornos aos agricultores;

- a carência de infraestrutura no município e em parte significativa do território prejudica a imagem divulgada externamente.

\section{Conclusões}

Após doze anos de existência da Acolhida na Colônia, registra-se rica experiência em vinte e quatro municípios catarinenses, beneficiando mais de 170 famílias de agricultores associados.

A Instituição foi criada para desenvolver o agroturismo, segmento de turismo no espaço rural, onde famílias de agricultores se organizam e estão dispostas a compartilhar seu modo de vida, patrimônio cultural e natural, mantendo as atividades econômicas, oferecendo produtos e serviços de qualidade, valorizando e respeitando ambiente e cultura local e proporcionando bem-estar aos envolvidos.

Para atingir este propósito a Acolhida criou uma carta de princípios, os quais devem ser seguidos por todos os associados. Entre os princípios orientadores, está a necessidade da produção orgânica, da ação cooperada e solidária entre os associados, o resgate e preservação cultural e ambiental. Também se desenvolvem estratégias e ações para que os princípios sejam respeitados pelos associados. Dentre as principais ações estão a formação e o intercâmbio realizado em cursos, palestras, 
Turismo de base comunitária em territórios rurais: caso da Associação de Agroturismo Acolhida na Colônia (SC)

seminários, visitas técnicas nacionais e internacionais direcionadas aos agricultores, assessoria técnica nas propriedades rurais, desenvolvimento de projetos especiais como o Roda d’Água (resgate e implantação de tecnologias de energia renovável), desenvolvimento de roteiros de turismo pedagógico para promover a educação ambiental e o desenvolvimento de circuitos de cicloturismo, dentre outras ações.

No campo das estratégias focadas na garantia dos princípios, destaca-se a existência de um referencial interno chamado de Caderno de Normas. Este documento apresenta as regras visando garantir qualidade e segurança para quem oferece o serviço e também para o cliente, além de assegurar o respeito aos princípios. Para garantir que as normas sejam seguidas pelos associados, todos assinam o termo de responsabilidade. Se, por um lado, o trabalho desenvolvido é sinônimo de resultados positivos, com geração de trabalho e renda nas propriedades e comunidades rurais, melhoria das condições ambientais e da imagem dos municípios, que de isolados passam a ser conhecidos regional e nacionalmente, por outro, há dificuldades internas entre associados e em relação aos municípios onde está inserida. No que diz respeito à relação entre associados, existe diferença de compreensão e adoção dos princípios. Isso tem sido gerado por visão oportunista e utilitarista da entidade, visto o espaço e reconhecimento conquistados pela instituição nos últimos anos, especialmente após 2007. A Acolhida é referência nacional no segmento turismo rural pelo Ministério do Turismo e tem sido objeto de diversas reportagens exibidas na mídia nacional, o que influencia sobremaneira na atração de visitantes para os municípios rurais. Além disso, a entidade disponibiliza uma série de produtos e serviços aos associados (central de reservas; web site; assistência técnica, etc). No que tange à relação da Acolhida com os municípios onde está inserida, se evidenciam conflitos. Isso acontece principalmente porque a entidade está pautada na conservação ambiental e os conflitos são relacionados a posição contrária sobre utilização de agrotóxicos, reflorestamento com espécies exóticas e desmatamento, exploração do subsolo para extração de argila e fosfato e construção de Pequena Centrais Hidrelétricas, o que leva agricultores associados e turistas conscientes se indisporem com a comunidade local.

Pode-se concluir que a complexidade que permeia os processos que objetivam promover o desenvolvimento territorial na perspectiva da sustentabilidade, privilegiam o turismo de base comunitária como um dos vetores, e isso tem significado ganhos reais para a experiência da Acolhida. Isso confirma que outra economia é possível, embora essa ainda seja conectada a economia de mercado.

\section{Referências bibliográficas}

ACOLHIDA NA COLÔNIA. Estatuto da Associação de Agroturismo Acolhida na Colônia. Santa Rosa de Lima, 1999.

BRANDÃO, C. R. A procura do Outro. Cadernos SESC de Cidadania, 2011. Disponível em http://sescsp.org.br/sesc/download/cadernos/turismo social 2011.pdf Acesso em: 15 de junho de 2012. 
BROSE, M. Agricultura familiar, desenvolvimento local e políticas públicas. Santa Cruz do Sul: EDUNISC, 1999. 347p.

BURSZTYN, I.; BARTHOLO, R.; DELAMARO, M. Turismo para quem? Sobre caminhos de desenvolvimento e alternativas para o turismo no Brasil. In: BARTHOLO, R.; SANSOLO, D.G.; BURSZTYN, I. Turismo de Base Comunitária: diversidade de oIhares e experiências brasileiras. Rio de Janeiro: Editora Letra e imagem, 2009, parte I, p.76 - 91.

CORIOLANO, L. N. M. T.; SILVA, S. C. B. Turismo e geografia: abordagens críticas. Fortaleza: Ed. UECE, 2005.

CORIOLANO, L. N. M. T. O turismo nos discursos, nas políticas e no combate à pobreza. São Paulo: Annablume, 2006. 238 p.

FAO/INCRA. Diretrizes de política agrária e desenvolvimento sustentável. Versão Resumida do Relatório Final do Projeto UTF/BRA/036. Brasília: FAO, 1994.

FAO/INCRA. Perfil da agricultura familiar no Brasil: dossier estatístico. Brasília, 1996. 24p.

GUZZATTI, C. T. O agroturismo como instrumento de desenvolvimento rural: sistematização e análise das estratégias utilizadas para a implantação de um programa de agroturismo nas encostas da Serra Geral. Dissertação (Mestrado) - Programa de Pós- Graduação em Engenharia de Produção. Centro Tecnológico, Universidade Federal de Santa Catarina, Florianópolis, 2003.

GUZZATTI, C. T. O agroturismo elemento dinamizador na construção de territórios rurais: o caso da Associação de Agroturismo Acolhida na Colônia em Santa Rosa de Lima (SC). Tese (Doutorado) - Programa de Pós-Graduação em Geografia. Centro de Filosofia e Ciências Humanas, Universidade Federal de Santa Catarina, Florianópolis, 2010.

IBGE, Censo Agropecuário. 2006.

SAMPAIO, C. A. C. Desenvolvimento sustentável e turismo: implicações de um novo estilo de desenvolvimento humano na atividade turística: uma introdução. Blumenau, SC: Edifurb; Florianópolis: Bernúncia, 2004. 132 p.

SAMPAIO, C.A.C. Gestão que privilegia uma outra economia: ecossocioeconomia das organizações. Blumenau: EDIFURB, 2010.

SILVEIRA, Marcos T. Política de turismo: oportunidades ao desenvolvimento local. In: RODRIGUES, Adyr B. (Org.) Turismo rural: práticas e perspectivas. São Paulo: Contexto, 2001. p. 133-150.

TRIGO, L. G. G. Turismo e Qualidade: Tendências contemporâneas. Campinas, SP: Papirus, 1993 (Coleção Turismo).

URRY, J. $\mathbf{O}$ olhar do turista: lazer e viagens nas sociedades contemporâneas. Trad.: Carlos Eugênio Marcondes de Moura. São Paulo: Studio Nobel: SESC, 1996. (Coleção Megalópolis). 
Turismo de base comunitária em territórios rurais: caso da Associação de Agroturismo Acolhida na Colônia (SC)

VEIGA, J.E. Cidades imaginárias: o Brasil é menos urbano do que se calcula. Campinas, SP: Autores Associados, 2002.

ZAQUAL, H. Do turismo de massa ao turismo situado: quais as transições? In: BARTHOLO, R.; SANSOLO, D.G.; BURSZTYN, I. Turismo de Base Comunitária: diversidade de olhares e experiências brasileiras. Rio de Janeiro: Editora Letra e imagem, 2009, parte I, p.55-75.

\section{Nota:}

${ }^{1}$ Os dados do censo agropecuário realizado em 2006 mostram a importância da agricultura familiar no Brasil e ajudam a justificar a necessidade de ações adequadas para a sua manutenção e o seu fortalecimento. Dos 5.175.489 estabelecimentos rurais existentes no País, 84$\%$, ou seja, 4.367.902 estabelecimentos eram classificados como familiares e ocupavam $24 \%$ da área de terras (80.250.453 hectares de um total de 329.941.393 hectares) (IBGE, 2006).

Thaise Costa Guzzatti: Universidade Regional de Blumenau, Blumenau, SC, Brasil. Email: thaise.acolhida@gmail.com

Link para o currículo Lattes: $\underline{\text { http://lattes.cnpq.br/3969366822285939 }}$

Carlos Alberto Cioce Sampaio: Universidade Federal do Paraná, Curitiba, PR

Email: carlos.cioce@gmail.com

Link para o currículo Lattes: $\underline{\text { http://lattes.cnpq.br/9034603212802471 }}$

Luzia Neide Menezes Teixeira Coriolano: Universidade Estadual do Ceará, Fortaleza, CE, Brasil.

Email: luzianeidecoriolano@gmail.com

Link para o currículo Lattes: http://lattes.cnpq.br/4477795642535596

Data de submissão: 30 de junho de 2012

Data de recebimento de correções: 10 de dezembro de 2012

Data do aceite: 10 de dezembro de 2012

Avaliado anonimamente 